\title{
cDNA cloning of bilirubin oxidase from Pleurotus ostreatus strain Shinshu and its expression in Aspergillus sojae: an efficient screening of transformants, using the laccase activity of bilirubin oxidase
}

\author{
Ikuko Masuda-Nishimura, ${ }^{*}$ Keiichi Ichikawa, Osamu Hatamoto, \\ Keietsu Abe, and Yasuji Koyama \\ Research and Development Division, Kikkoman Corporation, Noda 278-0037, Japan
}

(Received January 19, 1999; accepted April 15, 1999)

Key Words___Aspergillus sojae; bilirubin oxidase; laccase; Pleurotus ostreatus

Bilirubin oxidase (BOX; EC1.3.3.5) catalyzes the oxidation of bilirubin to biliverdin. It is used to measure the concentration of bilirubin in the serum to diagnose the degree of jaundice. It is also useful to remove bilirubin for the exact measurement of many clinical markers. Filamentous fungus Myrothecium verrucaria (Murao and Tanaka, 1982) and many basidiomycetes (Hiromi et al., 1992; Matsui et al., 1984; Uwajima and Hamamatsu, 1984) have been known as bilirubin oxidase producing fungi. Recently, BOX was purified and also characterized from Penicillium janthinellum (Seki et al., 1996). From Myrothecium, a BOX gene was cloned and expressed in yeast (Koikeda et al., 1993) and in Aspergillus (Xu et al., 1996).

Enzyme stable during a long-term storage in solution is generally required for a commercial diagnostic enzyme. We found that BOX from the Pleurotus ostreatus strain Shinshu was more stable than the other previously reported BOXs from other fungi during storage in solution. Since $P$. ostreatus strain Shinshu produced a small amount of BOX $(1 \mathrm{U} / \mathrm{ml}$ in 7-day culture), we cloned the cDNA of BOX from $P$. ostreatus strain Shinshu and tried to express it in Aspergillus sojae.

$P$. ostreatus strain Shinshu was aerobically cultured at $25^{\circ} \mathrm{C}$ in the $\mathrm{BOX}$ production medium $(6.0 \%$ soluble starch, $0.5 \%$ yeast extract, $0.1 \%$ sodium citrate, $0.05 \% \quad \mathrm{MgSO}_{4} \cdot 7 \mathrm{H}_{2} \mathrm{O}, \quad 0.0005 \% \quad \mathrm{CuSO}_{4} \cdot 5 \mathrm{H}_{2} \mathrm{O}$, and

\footnotetext{
* Address reprint requests to: Dr. Ikuko Masuda-Nishimura, Research and Development Division, Kikkoman Corporation, 399 Noda, Noda 278-0037, Japan.
}

$0.008 \% \mathrm{CaCl}_{2}$ ) for 5 days. After centrifugation, the supernatant was adjusted to $\mathrm{pH} 9.2$ and applied to a DEAE-cellulose column equilibrated with $0.01 \mathrm{M}$ carbonic buffer $(\mathrm{pH}$ 9.2). The enzyme was eluted by using a linear gradient of $0 \mathrm{M}$ to $0.6 \mathrm{M}$ ammonium sulfate. The fractions containing the bilirubin oxidase activities were concentrated and dialyzed against $0.01 \mathrm{M}$ carbonic buffer $(\mathrm{pH}$ 9.2). The concentrated fraction was applied to a Sephadex G-75 column equilibrated with $0.01 \mathrm{~m}$ carbonic buffer ( $\mathrm{pH}$ 9.2). Purified enzyme was obtained by concentrating and dialyzing the peak fractions. The molecular weight of the purified enzyme was 60,000 by SDS-PAGE (data not shown). The standard assay of BOX activity was performed as follows. A standard assay solution was prepared by dissolving $5 \mathrm{mg}$ of crystallized bilirubin in $2 \mathrm{ml}$ of $0.2 \mathrm{M}$ $\mathrm{NaOH}$ and diluted to $200 \mathrm{ml}$ by $0.1 \mathrm{~m}$ phosphate-buffer $(\mathrm{pH} 7.5)$. The reaction was performed at $37^{\circ} \mathrm{C}$ by adding $0.5 \mathrm{ml}$ of enzyme solution to $2 \mathrm{ml}$ of standard assay solution. The decrease in absorbance at $440 \mathrm{~nm}$ was measured. One unit is defined as the amount of enzyme that oxidizes $1 \mu \mathrm{mol}$ of bilirubin per min (the millimolar extinction coefficient of bilirubin under this assay condition is 40.93).

$\mathrm{N}$-terminal amino acid sequence of the purified enzyme was AIGPTGNMYIVNED. The purified BOX stored in the ammonium sulfate solution for a long period was applied to SDS-PAGE after removing the ammonium sulfate by ultrafiltration. We could not observe the band at the position of BOX, 60,000. Instead, we found a few bands at lower molecular weights (Fig. $1 \mathrm{~A})$. Long-term storage, the removal of ammonium 


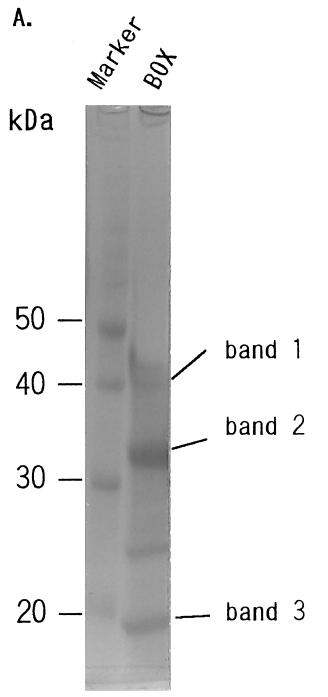

B.

band 1

Florida P0X2

Florida P0X1

band 2

Florida P0X2

Florida P0X1

band 3

Florida P0X2

Florida P0X1
XIPXVLVQGNKGDNFQXN

(64)SIPGVLVQGNKGDNFQLN (81)

(62) TLTGVLVQGNKGDNFQLN (79)

GPTGNMY I VNEDVSPDGF

(26) GPAGNMY IVNEDVSPDGF (43)

(26) GPTGDMYI VNEDVSPDGF (43)

XPSGXIYALEPNKVVEIS

(401)LPSGSIYELEANKVVEIS( 417)

(399)LPSGSIYSLEANKVVEIS (415)

Fig. 1. SDS-PAGE and the partial amino acid sequences of the BOX protein.

A: SDS-PAGE of the BOX after a long-term storage in ammonium sulfate solution. B: The similarities of the partial amino acid sequences of the BOX from strain Shinshu to those of the protein deduced from the pox2 and pox1 genes from strain Florida. The protein bands were eluted from the SDS-PAGE gel, and the partial amino acid sequences were determined. Florida POX2, the pox2 gene product from strain Florida; Florida POX1, the amino acid sequence deduced from the pox1 gene from strain Florida. $X$ indicates the amino acid that could not be determined during the peptide sequencing. Numbers in parentheses show those of the amino acid residue starting from the amino terminus.

sulfate from the BOX solution, or contamination of proteases might be responsible for the degradation of the BOX protein. The three protein bands were eluted from the SDS-PAGE gel, and the amino acid sequences were determined by the method of Kurth and Stoffel (1990). In a search of PIR and SWISS-PROT databases, a very high degree of homology was observed with the pox2 gene product (identified as laccase) and the protein sequence deduced from the pox1 gene (the protein is not identified) from $P$. ostreatus strain Florida (Giardina et al., 1995, 1996) (Fig. 1B). Therefore we examined whether the purified BOX had laccase activity by using the method of Giardina et al. (1995) with 2,2-azinobis-3-ethylbenzthiazoline-6-sulfonic acid or syringaldazine as the substrate. Laccase activity was detected. We also detected the laccase activity of BOX by the method of de Vries et al. (1986), using 4-amino-2,6-dibromophenol as the substrate. Consequently, we considered that BOX was the product of the pox 1 or pox2 gene.

To identify whether this BOX protein was the product of the pox 1 or pox 2 gene, we tried to clone these genes and determine the partial DNA sequences. The $\mathrm{N}$-terminals and central parts of the pox 1 and pox2 genes of $P$. ostreatus strain Florida showed a high similarity. However, the C-terminals were not conserved. We designed PCR primers, a common sense primer (5'-GCGTACTGCTACACCTACCACATATGTTTCCAGGCGCACGGATTCT-3'), from the N-terminal sequence, and respective antisense primers (5'-TA-
AGTAGGTAGACATATGCTAAGCTATGCC-3' and 5'GAAGTAGGAATAAGAAGAGGCATATGTTAGGACGGAACGATGCCTC-3') from the C-terminal sequences of the pox1 gene and pox2 gene. The pox 1 and pox2 genes were amplified by PCR $\left(94^{\circ} \mathrm{C}\right.$ for $30 \mathrm{~s}, 60^{\circ} \mathrm{C}$ for $2 \mathrm{~min}$, and $72^{\circ} \mathrm{C}$ for $2 \mathrm{~min}, 30$ cycles), using genomic DNA prepared from $P$. ostreatus strain Shinshu. We have determined approximately $300 \mathrm{bp}$ DNA sequences coding the $\mathrm{N}$-terminal regions of these PCR products. The deduced N-terminal amino acid sequences of the pox1 and pox2 genes are shown in Fig. 2. By comparing the deduced and experimentally determined $\mathrm{N}$-terminal amino acid sequences of BOX, we concluded that BOX was encoded by the pox2 gene.

BOX cDNA was cloned by RT-PCR, using the primers that were used to clone the genomic DNA. $P$. ostreatus strain Shinshu was cultured in the medium above described, and the total RNA was extracted with guanidinium thiocyanate, followed by centrifugation in cesium chloride solution. We performed RTPCR by using $1 \mu \mathrm{g}$ of total RNA as a template. A reverse extension reaction was done for $60 \mathrm{~min}$ at $42^{\circ} \mathrm{C}$. After 50 PCR cycles $\left(94^{\circ} \mathrm{C}\right.$ for $30 \mathrm{~s}, 60^{\circ} \mathrm{C}$ for $2 \mathrm{~min}$, and $72^{\circ} \mathrm{C}$ for $2 \mathrm{~min}$ ), pox $2 \mathrm{cDNA}$ was amplified, but the pox $1 \mathrm{cDNA}$ was not obtained. We considered that pox1 might not be expressed under this culture condition.

We determined the pox2 cDNA sequence (DDBJ/ EMBL/GenBank accession number AB020026), which 


\begin{tabular}{|c|c|}
\hline Shinshu POX2 & 1 MFPGARILATLTLALHLLHGTHAAIGPTGNMY IVNEDVSPDGFARSAVVA \\
\hline Shinshu P0X1 & 1 MFPGAR I LATLTLALHLLHGTHAA IGPTGDMY I VNEDVSPDGFNRSAVVA \\
\hline & 51 RSVPATDPTPATVS IPGVLVQGNKGDNFQLNVVNQLSDTTMLKTTSI. \\
\hline
\end{tabular}

Fig. 2. Comparison of the deduced amino acid sequences of the pox2 and pox1 genes from $P$. ostreatus strain Shinshu. Shinshu POX2, the deduced N-terminal amino acid sequence of the pox2 gene; Shinshu POX1, the deduced N-terminal amino acid sequence of the pox1 gene. The experimentally determined sequences are underlined.

encodes a protein consisting of 533 amino acids. We compared the deduced amino acid sequence of BOX to those of the other BOX and laccase (Fig. 3). A $97 \%$ homology was found between BOX from $P$. ostreatus strain Shinshu and laccase from strain Florida (Giardina et al., 1996). The homology among $P$. ostreatus BOX, Trachyderma tsunodae BOX (Iwamoto, 1997), and Schizophyllum commune laccase (Hatamoto et al., 1999) was relatively high (58-60\%). The homology between $P$. ostreatus BOX and $M$. verrucaria BOX (Koikeda et al., 1993) was relatively low (30\%).

Since we could not succeed in the BOX expression in Escherichia coli, we chose $A$. sojae as the host to express and secrete the BOX protein. The expression plasmid was constructed as follows. The cDNA that encoded the mature BOX protein was amplified by PCR. The PCR product was inserted into pTPT/ pUC19 (Hatamoto et al., 1999), which has a tannase promoter, tannase signal, and tannase terminator. $A$. sojae 1860 ( nia $^{-}$pro ${ }^{L}$ ), which has no laccase activity (Hatamoto et al., 1999), was cotransformed with this expression plasmid and niaD plasmid (Hatamoto et al., 1996) by the method of Campbell et al. (1989). The nia $D^{+}$transformants were transferred to the assay plates containing gallic acid $\left(1.2 \%\left(\mathrm{NH}_{4}\right)_{2} \mathrm{HPO}_{4}\right.$, $0.2 \% \quad \mathrm{KH}_{2} \mathrm{PO}_{4}, 0.1 \% \mathrm{MgSO}_{4} \cdot 7 \mathrm{H}_{2} \mathrm{O}, 5.3 \%$ glucose, $1.0 \%$ gallic acid, $\left.0.005 \% \mathrm{CuSO}_{4} \cdot 5 \mathrm{H}_{2} \mathrm{O}, \mathrm{pH} 6.0\right)$. If the transformant produced and secreted $\mathrm{BOX}$ into the medium, gallic acid would be oxidized and turn dark brown because of the laccase activity of BOX. The expression levels of the laccase activity of the transformants could be estimated by the intensity of the color.

Thirty-six transformants of $59 \mathrm{niaD}^{+}$transformants showed a brown color. Four that showed an intense brown color were selected, and a single colony isolation was performed. We selected the transformant, B222, which showed the darkest color (Fig. 4A). Southern-blot analysis of the chromosomal DNA from the transformant B222 indicated that at least 3 copies of the BOX gene were integrated into the chromosomes (Fig. 4B). B222 was cultured in the BOX production medium containing $2 \%$ tannic acid as an inducer. The BOX activity of B222 was $0.6 \mathrm{U} / \mathrm{ml}$ after 6 days.

In this report, we succeeded in cloning the BOX
cDNA from $P$. ostreatus strain Shinshu and its expression in A. sojae. Since a very high degree of homology was observed between the partial amino acid sequences of BOX and laccase, we found that the BOX from $P$. ostreatus strain Shinshu had laccase activity. It is already known that BOX from filamentous fungi $M$. verrucaria has laccase activity (Xu et al., 1996). On the other hand, it was reported that laccase from basidiomycete Polyporus has no BOX activity (Tanaka and Murao, 1983). Although many reports have been made about laccases from basidiomycetes (Coll et al., 1993; Heinzkill et al., 1998; Kojima et al., 1990; Sannia et al., 1986), no information about the BOX activity has been presented, and this is first report that the laccase from basidiomycete has BOX activity. In Coprinus cinereus (Ducros et al., 1998; Uwajima and Hamamatsu, 1984), Schizophillum commune (de Vries et al., 1986; Matsui et al., 1984), and Trametes versicolor (Bourbonnais et al., 1995; Uwajima and Hamamatsu, 1984), laccase and BOX were separately reported. It would be very interesting to examine whether these laccases have BOX activities. We recently succeeded in cloning the laccase cDNA from $S$. commune and expressed it in $A$. sojae (Hatamoto et al., 1999). S. commune laccase had no BOX activity, though the deduced amino acid sequence showed a high degree of homology (58-60\%) with those of $P$. ostreatus BOX and Trachyderma tsunodae BOX. Because some basidiomycetes produce several laccases, the BOX of $S$. commune may be encoded in other laccase genes. Amino acid residues that are conserved in $P$. ostreatus BOX and $T$. tsunodae BOX but not in $S$. commune laccase may be involved in substrate specificity, or the active sites for bilirubin and polyphenols may be different.

Transformants producing BOX were successfully obtained by the screening of transformants, using laccase activity of BOX as a selection marker. Further studies, such as improving culture conditions and increasing copy numbers of the BOX gene in transformants, will enable us to obtain a higher productivity of BOX at a commercial level. 


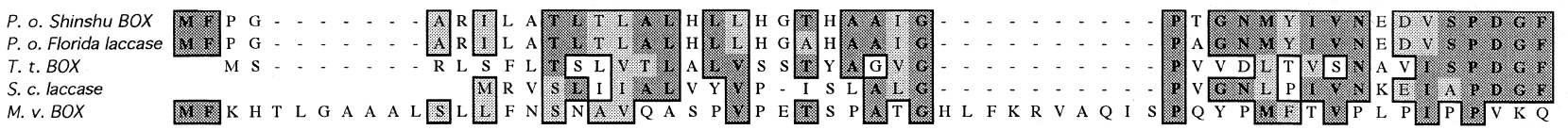

201

P. o. Shinshu BOX P. o. Florida laccase

P. o. Shinshu BOX P. o. Florida laccase

P. o. Shinshu BOX P. o. Florida laccase T. t. BOX S. c. laccase M. v. BOX
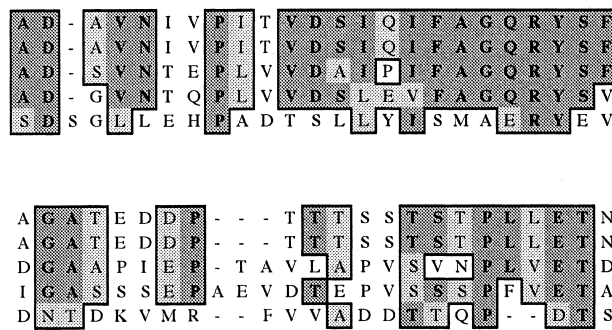

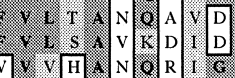

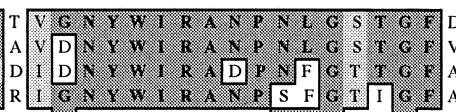

314

P. o. Shinshu BOX P. o. Florida laccase

P. o. Shinshu BOX P. o. Florida laccase

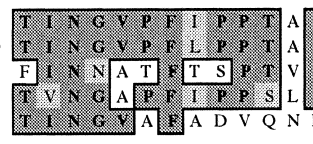

P. o. Shinshu BOX P. o. Florida laccase

P. O. Shinshu BOX
P. o. Florida laccase

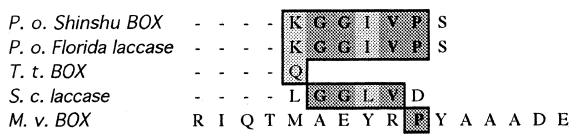

Fig. 3. Alignment of the BOX from $P$. ostreatus strain Shinshu with the other BOXs and laccases.

P. o. Shinshu BOX, BOX from the Pleurotus ostreatus strain Shinshu (AB020026); P. o. Florida laccase, laccase from the Pleurotus ostreatus strain Florida (Z34848); T. t. BOX, BOX from Trachyderma tsunodae (AB006824); S. c. laccase, laccase from Schizophyllum commune (AB015758); M. v. BOX, BOX from Myrothecium verrucaria (D12579). The accession numbers in $\mathrm{DDBJ} / \mathrm{EMBL} /$ GenBank databases are shown in parentheses. 
A.

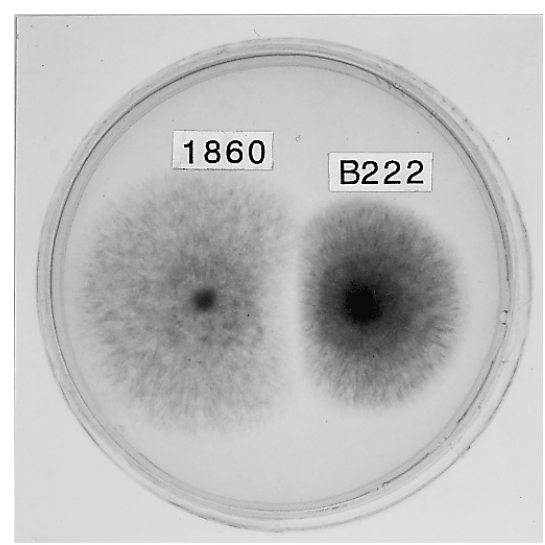

B.

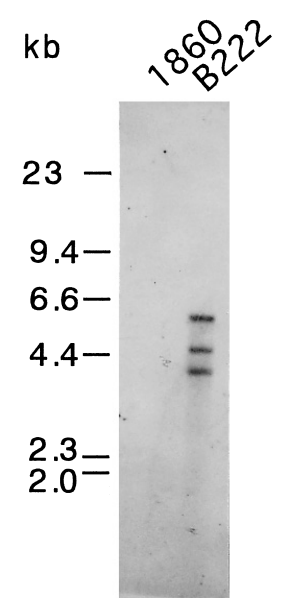

Fig. 4. Plate assay and Southern-blot analysis of the transformant B222.

A: Plate assay of the transformant by laccase activity. 1860, $A$. sojae 1860 (the host strain); B222, a transformant. B: Southern-blot analysis of B222. Chromosomal DNAs digested with EcoRI were loaded onto each lane, and the $1.2 \mathrm{~kb} \mathrm{BamHI-Ndel} \mathrm{fragment} \mathrm{of} \mathrm{the}$ BOX cDNA labeled with digoxigenin was used as a probe. 1860, $A$. sojae 1860 (the host strain); B222, the transformant.

\section{References}

Bourbonnais, R., Paice, M. G., Reid, I. D., Lanthier, P., and Yaguchi, M. (1995) Lignin oxidation by laccase isozyme from Trametes versicolor and role of the mediator 2,2'-azinobis(3-ethylbenzthiazoline-6-sulfonate) in kraft lignin depolymerization. Appl. Environ. Microbiol., 61, 1876-1880.

Campbell, E. I., Unkles, S. E., Macro, J. A., van den Hondel, C., Contreras, R., and Kinghorn, J. R. (1989) Improved transformation efficiency of Aspergillus niger using the homologus niaD gene for nitrate reductase. Curr. Genet., 16, 53-56.

Coll, P. M., Fernandez-Abalos, J. M., Villanueva, J. R., Santamaria, R., and Perez, P. (1993) Purification and characterization of a phenoloxidase (laccase) from the lignin-degrading basidiomycete PM1 (CECT 2971). Appl. Environ. Microbiol., 59, 2607-2613.

de Vries, O. M. H., Kooistra, W. H. C. F., and Wessels, J. G. H. (1986) Formation of an extracellular laccase by a Schizophyl- lum commune dikaryon. J. Gen. Microbiol., 132, 2817-2826.

Ducros, V., Brzozowski, A. M., Wilson, K. S., Brown, S. H., Ostergaard, P., Schneider, P., Yaver, D. S., Pedersen, A. H., and Davies, G. J. (1998) Crystal structure of the type-2 Cu depleted laccase from Coprinus cinereus at $2.2 \AA$ resolution. Nat. Struct. Biol., 5, 310-316.

Giardina, P., Aurilia, V., Cannio, R., Marzullo, L., Amoresano, A., Siciliano, R., Pucci, P., and Sannia, G. (1996) The gene, protein and glycan structures of laccase from Pleurotus ostreatus. Eur. J. Biochem., 235, 508-515.

Giardina, P., Cannio, R., Martirani, L., Marzullo, L., Palmieri, G., and Sannia, G. (1995) Cloning and sequencing of a laccase gene from the lignin-degrading basidomycete Pleurotus ostreatus. Appl. Environ. Microbiol., 61, 2408-2413.

Hatamoto, O., Sekine, H., Nakano, E., and Abe, K. (1999) Cloning and expression of CDNA encoding the laccase from Schizophyllum commune. Biosci. Biotech. Biochem., 63, 58-64.

Hatamoto, O., Watarai, T., Kikuchi, M., Mizusawa, K., and Sekine, $\mathrm{H}$. (1996) Cloning and sequencing of the gene encoding tannase and structural study of the tannase subunit from $A s-$ pergillus oryzae. Gene, 175, 215-221.

Heinzkill, M., Bech, L., Halkier, T., Schneider, P., and Anke, T. (1998) Characterization of laccases and peroxidases from wood-rotting fungi (family Coprinaceae). Appl. Environ. Microbiol., 64, 1601-1606.

Hiromi, K., Yamaguchi, Y., Sugiura, Y., Iwamoto, H., and Hirose, J. (1992) Bilirubin oxidase from Trachyderma tsunodae K-2593, a multi-copper enzyme. Biosci. Biotech. Biochem., 56, 13491350.

Iwamoto, H. (1997) Accession number AB006824. Submitted (26AUG-1997) to the DDBJ/EMBL/GenBank databases.

Koikeda, S., Ando, K., Kaji, H., Inoue, T., Murao, S., Takeuchi, K., and Samejima, T. (1993) Molecular cloning of the gene for bilirubin oxidase from Myrothecium verrucaria and its expression in yeast. J. Biol. Chem., 268, 18801-18809.

Kojima, Y., Tsukuda, Y., Kawai, Y., Tsukamoto, A., Sugiura, J., Sakaino, M., and Kita, Y. (1990) Cloning, sequence analysis, and expression of lignolytic phenoloxidase genes of the whiterot basidiomycete Coriolus hirsutus. J. Biol. Chem., 265, 15224-15230.

Kurth, J. and Stoffel, W. (1990) A facile method for the isolation and preperation of proteins and peptides for sequence analysis in picomolar range. Biol. Chem. Hoppe-Seyler, 371, 675-685.

Matsui, Y., Satoh, T., and Nakajima, K. (1984) Jpn. Patent. Japan Kokai Tokkyo Koho, 59-135886.

Murao, S. and Tanaka, N. (1982) Isolation and identification of a microorganism producing bilirubin oxidase. Agric. Biol. Chem., 46, 2031-2034.

Sannia, G., Giardina, P., Luna, M., Rossi, M., and Buonocore, V. (1986) Laccase from Pleurotus ostreatus. Biotechnol. Lett., 8, 797-800.

Seki, Y., Takeguchi, M., and Okura, I. (1996) Purification and properties of bilirubin oxidase from Penicillium janthinellum. $J$. Biotechnol., 46, 145-151.

Tanaka, N. and Murao, S. (1983) Difference between various copper-containing enzymes (Polyporus laccase, mushroom tyrosinase and cucumber ascorbate oxidase) and bilirubin oxidase. Agric. Biol. Chem., 47, 1627-1628.

Uwajima, T. and Hamamatsu, M. (1984) Jpn. Patent. Japan Kokai Tokkyo Koho, 59-198971.

Xu, F., Shin, W., Brown, S., Wahleithner, J. A., Sundaram, U. M., and Solomon, E. I. (1996) A study of a series of recombinant fungal laccase and bilirubin oxidase that exhibit significant differences in redox potential, substrate specificity, and stability. Biochim. Biophys. Acta, 1292, 303-311. 